\title{
ANAEROBIC CO-DIGESTION OF A SINGLE SOURCE OILY WASTE AND HIGH STRENGTH PET FOOD WASTEWATER: A STUDY OF FAILURE AND REVIVAL OF A FULL SCALE DIGESTER
}

\author{
C. Acharya ${ }^{1}$, R. Kurian ${ }^{2}$ \\ ${ }^{1}$ Stantec Consulting, 800-171 Queens Avenue, London, On N6A 5J7, Canada \\ ${ }^{2}$ Earth Tech Canada Inc., 105 Commerce Valley Dr. West, On L3T 7W3, Canada
}

\begin{abstract}
This paper focuses on the revival of a formerly failed digester of $1800 \mathrm{~m}^{3}$ volume. The most obvious cause of failure was identified to be due to capping caused by foam and scum, as result of attempting to treat oil rich, high strength wastewater. The revival was affected by implementing co-digestion in a 3 -step remedial procedure. Though in the typical sense, codigestion involves separate waste streams, here a single waste stream was manipulated to apply the concept of co-digestion. Through the virtual co-digestion the digester presently succeeds to treat the daily plant effluent flows of $50 \mathrm{~m}^{3}$ with COD $>45 \mathrm{~g} / \mathrm{L}$ and around 10 tons of sludge/day which has around $20 \%$ oil and fat, exhibiting a COD removal $>90 \%$. The digester operates at $35 \pm 1{ }^{0} \mathrm{C}$ and HRT of 30 days with loading rates of $3.4 \mathrm{~kg} \mathrm{COD} / \mathrm{m}^{3} \mathrm{~d}$ and $1.3 \mathrm{~kg} \mathrm{O \& G} / \mathrm{m}^{3} \mathrm{~d}$. The biogas generated from this digester is sufficient to operate a $40 \mathrm{hp}$ boiler at $100 \mathrm{psi}$.
\end{abstract}

\section{KEYWORDS}

Co-digestion, anaerobic, high strength wastewater, oil and grease, revival of digesters

\section{INTRODUCTION}

Anaerobic digestion is a particularly attractive treatment solution for high strength wastewaters due to the operational economy and generation of biogas. However, in the absence of close monitoring and operational expertise, large numbers of anaerobic systems have failed across North America. Industrial wastes are generally deficient in methanogens. Hence, industrial digesters require to be seeded with methanogen- rich sludge such as primary sludges from municipal digesters or fresh cow manure. Above this, anaerobic processes' susceptibility to high oil and grease has been widely recognized [1].

Animal oil and grease are highly organic and therefore an excellent source to generate biogas. But their hydrophobic nature limits their availability for biodegradation, and results in floating and foaming in both aerobic and anaerobic systems. To treat oil and grease rich wastewaters biologically the most important criteria to be met are stable and active biomass and proper mixing as emphasized by Hashimoto [2]. In spite of the numerous reports of failed anaerobic treatment systems in the presence of oil and grease, Fermandez et al. [3] successfully treated up to $28 \%$ animal fats anaerobically by co-digesting it with cow manure. Similarly Kim et al [4] proved co-digestion of food wastes with sewage sludge to enhance biogas generation and solids destruction. Co-digestion is the process of digesting two separate waste streams in a single bioreactor. In co-digestion, the favorable wastes aid stabilization of the biological system and complex wastes are 'co-digested'. 
The anaerobic digester of $1800 \mathrm{~m}^{3}$ volumetric capacity had failed to treat the pet food plant effluent for 4 years when the concept of co-digestion was employed in the, now, successful attempt to revive this digester. In this study co-digestion was implemented not in the typical style of multiple feed streams but by manipulating the single waste stream. A 3-step remedial procedure was undertaken to implement co-digestion. The first step involved the separation of oil from the waste stream to generate relatively oil-free wastewater. In the second step the digester was acclimatized to the relatively oil-free wastewater stream, and in the third step co-digestion of an oil rich stream was achieved.

The pet food industry effluent treated in this digester is characterized by O\&G concentrations as high as $60000 \mathrm{mg} / \mathrm{L}$, total COD, BOD, TKN and ammonia concentrations of $100000 \mathrm{mg} / \mathrm{L}$, $80000 \mathrm{mg} / \mathrm{L}, 2500 \mathrm{mg} / \mathrm{L}$ and $1200 \mathrm{mg} / \mathrm{L}$ respectively (Table1). The successful implementation of co-digestion (in a broader interpretation) in this case offers an innovative solution for many failed anaerobic digesters across North America.

\section{MATERIALS AND METHODS}

The pet food industry operates 24 hours a day, 5 days a week with flows and strengths of the wastewater varying depending on the production cycle. The anaerobic digester has been in operation for a period of 5 years.

\section{ANAERobic Digester}

The anaerobic digester, built in concrete, has a volume of $1800 \mathrm{~m}^{3}$ is equipped with a $20 \mathrm{hp}$ top entry mixer and operates at 30 day HRT (Figure1). Content of the top entry, bottom exit digester remains complete mixed with provision of 4 vertical baffles. As there are no equalization tanks the plant effluent is fed directly into the digester. The digester temperature is maintained at $35 \pm 1$ ${ }^{0} \mathrm{C}$ by regulating influent temperature and direct steam heating in the digester. The external surface of the digester is insulated to minimize heat losses. The digester tank is provided with pressure relief valves and pressure control valves to maintain positive pressure $15 \mathrm{~mm}$ water column in the digester head space. Currently the biogas generated is flared though in future it is intended to fuel boilers. Online gauges measure instantaneous and cumulative biogas flows, digester temperature, pressure and level.

Upstream to the digester, free oil is recovered by heating the wastewater. Recently a dissolved air flotation unit (DAF) was installed to treat the wastewater prior to feeding the digester to separate oil and grease. A series of heat exchangers operate to maintain digester feed temperature at $35 \pm 1{ }^{0} \mathrm{C}$. Digester effluent is collected and stored year round in two $4500 \mathrm{~m}^{3}$ concrete tanks, and land applied in accordance to the governmental regulations.

The digester operations were monitored, and samples of DAF influent, DAF effluent and digester effluent were collected once a week in phase $1 \& 2$ and 3 to 5 times in phase 3 . Parameters analyzed included COD, VFA, alkalinity, TS, O\&G and ammonia. All analyses were performed in house or by certified laboratories as per standard procedures [5]. The digester manhole was opened every 3 to 6 months for visual inspection. 


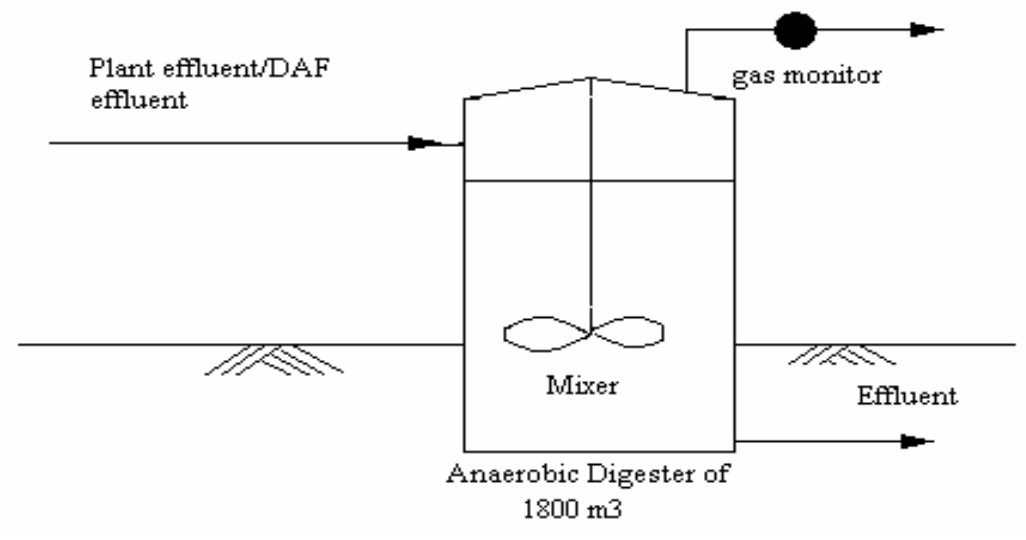

Figure 1: System diagram of on-site anaerobic digester

\section{RESULTS AND DISCUSSION}

The anaerobic digester treating oily pet food wastewater failed as a result of oil and grease capping. The paper discusses the initial start up leading up to failure and the following 3-step remedial measures taken to revive the digester.

Table 1: Raw and DAF effluent Characteristics

\begin{tabular}{|c|c|c|c|c|}
\hline \multirow{2}{*}{ Parameters } & \multicolumn{2}{|c|}{ Raw wastewater } & \multicolumn{2}{c|}{ DAF Effluent } \\
\cline { 2 - 5 } & Range & Average & Range & Average \\
\hline TSS (mg/l) & $17311-61700$ & 56857 & $1150-12866$ & 4651 \\
\hline VSS (mg/l) & $15180-59800$ & 54383 & $1100-10966$ & 4571 \\
\hline TCOD (mg/l) & $74925-154100$ & 96660 & $10025-50500$ & 21000 \\
\hline SCOD (mg/l) & $13125-18450$ & 16757 & $6860-19980$ & 12300 \\
\hline Ammonia- N (mg/l) & $797-1400$ & 1060 & $640-1440$ & 1030 \\
\hline O \& G (mg/l) & $23253-53000$ & 38800 & $600-6000$ & 1230 \\
\hline
\end{tabular}

\section{INITIAL DIGESTER START-UP AND FAILURE}

The digester was initially seeded with approximately $40 \mathrm{~m}^{3}$ of sludge from a local municipal digester of $\sim 3 \%$ biosolids. The high rate of gas generation, $100 \mathrm{~m}^{3} / \mathrm{hr}$, during the first 2 weeks was interpreted as well-adapted biological activity. The active digester volume being $900 \mathrm{~m}^{3}$ in fifteen days, the gas generation translates to very high COD destruction rate of $6.2 \mathrm{~kg} / \mathrm{m}^{3}$.day, which is around two times higher than $3.1 \mathrm{~kg} / \mathrm{m}^{3}$.day observed in digestion of similar oily wastes [3]. 
After this period a steep drop in gas generation was observed, reaching zero within 30 days. Despite such a 'loud' warning sign the operator continued feeding the digester. The digester showed no sign of recovery, and $\mathrm{pH}$ dropped to 6.2 and volatile fatty acids (VFA) to alkalinity ratio increased 2.5. The effluent COD and TSS were measured to be around $60,000 \mathrm{mg} / \mathrm{L}$ and $25,000 \mathrm{mg} / \mathrm{L}$ respectively. Apparent reduction in COD and TSS did not match with gas generation data. These pointed to accumulations in the system. A visual inspection after 3 months revealed a stagnant and dense mass of oil and grease found floating on the top, indicating improper mixing.

Studying the premature failure of the digester led to the impression that proper mixing was achieved in a half filled digester resulting in enhanced biological activity. But with the continual addition of wastewater the mixing was compromised affecting a separation of oil and grease. The floating layer resulted in a gas cap, reducing the $\mathrm{pH}$ due to unreleased $\mathrm{CO}_{2}$ proving toxic to methanogens. Solids and oil and grease mass balance (not shown here) indicated the floating scum layer was equivalent to more than half of the reactor volume. In spite of experimenting with various commercially available cultures targeting oily wastes, the gas generation was almost remained less than $30 \mathrm{~m}^{3} /$ day and COD removal less then $10 \%$ across the digester for the next 4 years.

\section{TROUBLESHOOTING}

Over the four years the industry attempted (not discussed here) to address the symptoms individually such as very high VFA to alkalinity ratio $(>2)$, lower $\mathrm{pH}(<6)$ and insufficient active biomass in the digester. Failure of these attempts proved inability of the digester to treat very high oil concentrations.

The failed digester was revived by adopting a procedure to create an oil free milieu in the digester, so that later feed of any oil would dilute it sufficiently to digest it. The three step procedure involved physical removal of the oil \& grease from the digester, stabilization of biological system and co-digestion of oil and grease.

\section{Step 1: Physical Removal of Oil and Grease}

As mentioned above, the scum layer filled more than half of the digester volume and proper mixing of the digester content is quintessential for full biological functionality of the digester. The existing $20 \mathrm{hp}$ top entry mixer was designed to mix water-like media, and was incapable of mixing the oily scum. Hence, it was decided to physically remove the accumulated oily sludge from the digester. Reactor oil and grease was removed by displacing it with relatively oil free wastewater.

\section{Oil separation from wastewater using DAF}

A DAF system was installed upstream of the digester. The DAF successfully removed more than $95 \%$ of free oil and grease from the plant effluent (Table 1). Treating $60 \mathrm{~m}^{3} /$ day of raw wastewater, the DAF created two waste streams i.e. $10 \mathrm{~m}^{3} /$ day (or 10 tons/day) oil rich DAF 
sludge and $50 \mathrm{~m}^{3} /$ day of relatively oil free DAF effluent. Characteristics of both streams are presented in Table 2.

\section{Displacement of oil and grease from the digester}

Around $50 \%$ of the digester content was drained using existing gravity drain line. Reduced water level enhanced mixing in the digester. Digester was then filled with DAF effluent rather than the raw wastewater, as done previously. Such draining and filling were repeated around four times to wash out or dilute any remnants of oil and grease in the digester.

Table 2: Characteristics of DAF sludge and DAF effluent

\begin{tabular}{|c|c|c|c|c|}
\hline \multirow{2}{*}{ Parameters } & \multicolumn{2}{|c|}{ DAF Sludge } & \multicolumn{2}{c|}{ DAF Effluent (mg/L) } \\
\cline { 2 - 5 } & Range & Average & Range & Average \\
\hline TSS & $4-7 \%$ & $5 \%$ & $1150-12866 \mathrm{mg} / \mathrm{L}$ & $4651 \mathrm{mg} / \mathrm{L}$ \\
\hline VSS & $3-6 \%$ & $4 \%$ & $1100-10966 \mathrm{mg} / \mathrm{L}$ & $4571 \mathrm{mg} / \mathrm{L}$ \\
\hline O \& G & $20-30 \%$ & $25 \%$ & $10025-50500 \mathrm{mg} / \mathrm{L}$ & $21000 \mathrm{mg} / \mathrm{L}$ \\
\hline TCOD & $300-500 \mathrm{~g} / \mathrm{L}$ & $450 \mathrm{~g} / \mathrm{L}$ & $600-6000 \mathrm{mg} / \mathrm{L}$ & $1230 \mathrm{mg} / \mathrm{L}$ \\
\hline
\end{tabular}

\section{STEP 2: Biological StabiLization OF Digester}

The second step was conducted in two phases.

\section{Phase 1: No Feed}

In the first phase the digester was reseeded with the sludge from a local municipal digester. To cultivate sufficiently variable consortium 25 gallons of fresh cow manure was added to the digester every day continuously for a week. The digester was then allowed to sit without any feed for 100 days.

The gas generation during this period, as visible from Table 3, was minimal. The aim of this procedure was to allow an acclimatization period for the bacteria. The first phase started off with very high VFAs and acid to alkalinity ratio $(>1.52)$. At the end of this phase the acid to alkalinity ratio was close to 1 , which was an improvement though not ideal for anaerobic treatment. The total ambient COD in the reactor reduced from $>60,000 \mathrm{mg} / \mathrm{L}$ to $<30,000 \mathrm{mg} / \mathrm{L}$ (Figure 2).

\section{Phase 2: Feeding DAF Effluent}

The second phase started with the gradual feed of DAF effluent to the digester. Initially only $20 \%$ of the DAF effluent was fed to the digester, closely monitoring the acid to alkalinity ratio and gas generation. Feed was reduced further at times when the acid to alkalinity ratio exceeded 1 and gas generation reduced. 
Table 3: Digester performance during different phases

\begin{tabular}{|l|c|c|c|}
\hline \multirow{2}{*}{} & \multicolumn{2}{|c|}{ Step 2 } & Step 3 \\
\cline { 2 - 4 } & Phase 1. & Phase 2. & Phase 3. \\
\hline Feed Stream & No Feed & DAF Effluent & $\begin{array}{c}\text { DAF Effluent } \\
\text { +DAF Sludge }\end{array}$ \\
\hline Effluent COD (mg/L) & 3200 & 4500 & 9000 \\
\hline $\begin{array}{l}\text { Average Gas Generation } \\
\text { (m } \text { }^{\text {/hr })}\end{array}$ & 21500 & 10072 & 9500 \\
\hline Total VFA (mg/L) & 9170 & 26 & 70 \\
\hline Alkalinity (mg CaCO $/ \mathrm{L})$ & 6000 & 1197 & 1285 \\
\hline VFA to Alkalinity ratio & 1.52 & 7660 & 7180 \\
\hline pH & 7.2 & 0.16 & 0.18 \\
\hline
\end{tabular}

As the gas generation picked up and the acid to alkalinity ratios decreased, complimented by COD destruction and confirmed by stable VSS measurements the feed was increased. Within three months $100 \%$ of the DAF effluent was fed to the digester without any adverse effects.

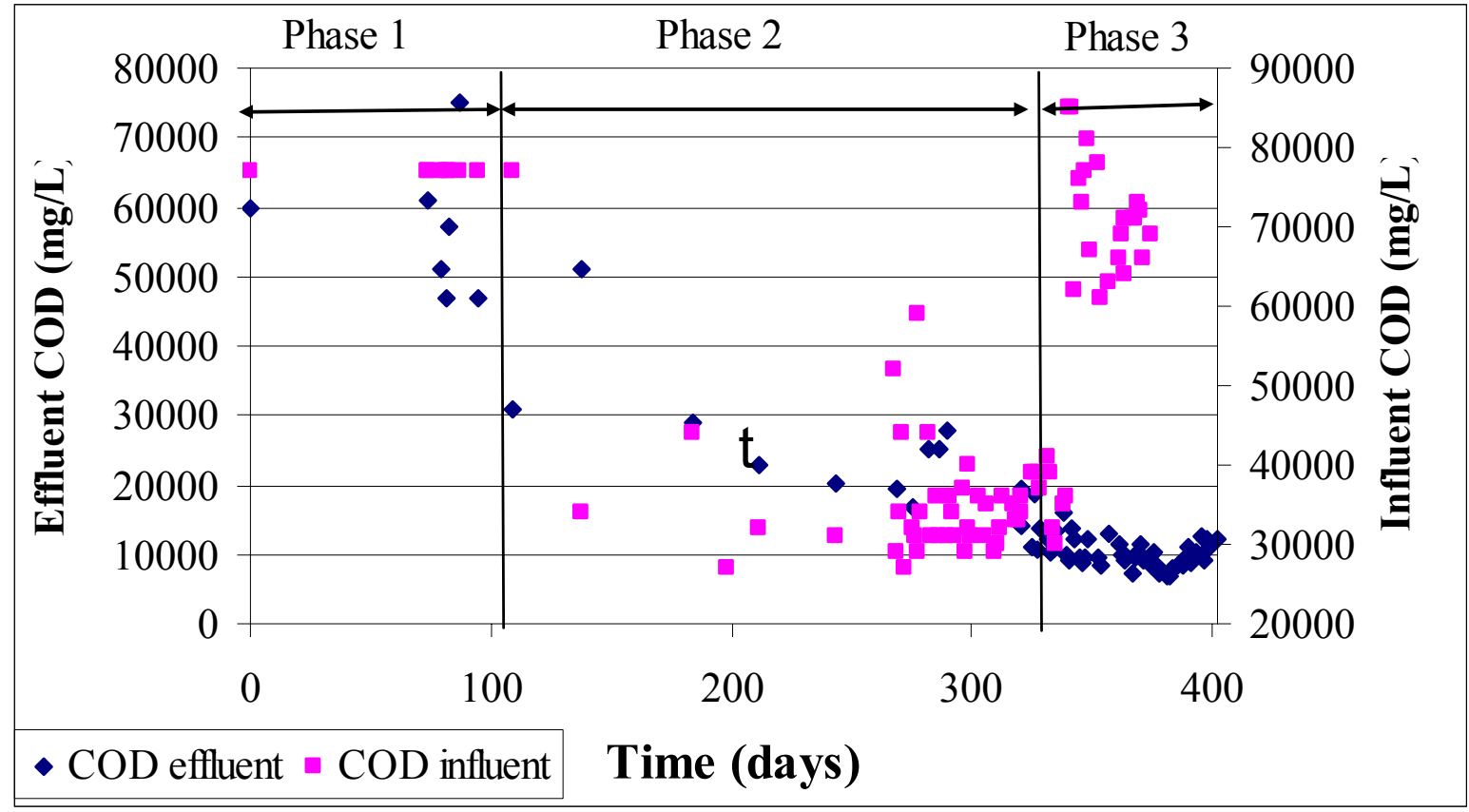

Figure 2: Trend of total COD in digester over time. 


\section{STEP 3: DAF EFFLUENT AND DAF SLUdGe Co-Digestion}

In the final step small additions of oil was allowed into the digester by bypassing the DAF for short periods of time, i.e. DAF sludge generation was gradually reduced This is virtually equivalent to blending two separate streams with gradual increments in a co-digestion scenario. The daily gas generation (phase 3 in Table 3 ) was converted into equivalent COD and tallied with measured effluent COD to ensure the influent was being degraded to acceptable levels. The results attest the applicability of co-digestion in this case, even though co-digestion was not applied in the conventional sense.

During the third step the oil and grease was gradually increased from $1 \%$ to $8 \%$ accompanied by close monitoring. In several instances, the DAF was bypassed completely resulting in a total COD and O\&G loading rate of $3.4 \mathrm{~kg} / \mathrm{m}^{3} \mathrm{~d}$ and $1.3 \mathrm{~kg} / \mathrm{m}^{3} \mathrm{~d}$ respectively at $20 \%$ blend ratio (i.e. $20 \%$ sludge $+80 \% \mathrm{v} / \mathrm{v}$ wastewater). At steady state in phase 3 , the digester achieved $>90 \%$ COD and $>95 \%$ oil and grease removal. The digester continues to operate successfully for over 6 months.

\section{CONCLUSIONS}

- Contrary to common belief the anaerobic digesters are incapable of treating oily wastewaters this study proves otherwise. Lack of operational expertise and insufficient control/monitoring during start up are the major reasons of anaerobic digester failures.

- Anaerobic treatment of oily wastewater is most vulnerable during the start up phase. If not monitored and controlled closely, formation of scum layer impedes mixing leading to drastic failures.

- Co-digestion, even if not in the strictest sense, is a solution to treating oily wastewaters anaerobically.

\section{REFERENCE}

[1] Liu L.; Nakhla G.; Bassi A. (2004), The treatability study of a high strength pet food waste water: A continuous flow aerobic system performance evaluation, Enviro.Tech. 25, 577-588.

[2] Hashimoto, A.G. (1983). Effect of mixing duration and vacuum on methane production rate from beef cattle waste. Biotech. Bioeng. 24, 9-23.

[3] Fermandez A, Sanchez A, Font X (2005), Anaerobic co-digestion of a simulated organic fraction of municipal solid wastes and animal fats, Biochem. Eng. Journal 26, 22-28

[4] Kim H., Han S., Shin H., Kim H., Han S., Bae B., Shin H.(2004) Anaerobic co-digestion of sewage sludge and food waste using two-stage anaerobic sequencing batch reactor processes, Proceeding of 10th World Congress - Anaerobic digestion 2004, Centre MontRoyal Montreal, Canada, 29 Aug - 2 Sep., 2004. 
[5] APHA -AWWA - WPCF, 1998. Standard Method for Examination of Water and wastewater, $20^{\text {th }}$-ed, American Public Health Association, Washington, D.C, USA.

[6] Gerardi M.H. (2003), The microbiology of Anaerobic Digesters, John Wiley \& Sons, Inc., New York. 